\title{
A Toolbox for Nodule Development Studies in Chickpea: A Hairy-Root Transformation Protocol and an Efficient Laboratory Strain of Mesorhizobium sp.
}

\author{
Drishti Mandal and Senjuti Sinharoy ${ }^{\dagger}$ \\ National Institute of Plant Genome Research, New Delhi 110067, India \\ Accepted 1 November 2018.
}

\begin{abstract}
A Mesorhizobium sp. produces root nodules in chickpea. Chickpea and model legume Medicago truncatula are members of the inverted repeat-lacking clade (IRLC). The rhizobia, after internalization into the plant cell, are called bacteroids. Nodule-specific cysteine-rich peptides in IRLC legumes guide bacteroids to a terminally differentiated swollen (TDS) form. Bacteroids in chickpea are less TDS than those in Medicago spp. Nodule development in chickpea indicates recent evolutionary diversification and merits further study. A hairy-root transformation protocol and an efficient laboratory strain are prerequisites for performing any genetic study on nodulation. We have standardized a protocol for composite plant generation in chickpea with a transformation frequency above $50 \%$, as shown by fluorescent markers. This protocol also works well in different ecotypes of chickpea. Localization of subcellular markers in these transformed roots is similar to the localization observed in transformed Medicago roots. When checked inside transformed nodules, peroxisomes were concentrated along the periphery of the nodules, while endoplasmic reticulum and Golgi bodies surrounded the symbiosomes. Different Mesorhizobium strains were evaluated for their ability to initiate nodule development and efficiency of nitrogen fixation. Inoculation with different strains resulted in different shapes of TDS bacteroids with variable nitrogen fixation. Our study provides a toolbox to study nodule development in the crop legume chickpea.
\end{abstract}

Root nodule symbiosis (RNS) is the most successful metabolism-dependent symbiosis on the earth. Leguminous plants get reduced nitrogen directly from RNS at the expense of photosynthate (Werner et al. 2015). The staple crop chickpea (Cicer arietinum) $(2 \mathrm{n}=2 \mathrm{x}=16)$ is the world's second largest cultivated legume. Chickpea seeds are a valuable source of dietary protein in lower socio-economic classes. The predicted genome size of chickpea is approximately $740 \mathrm{Mb}$. Due to the

${ }^{\dagger}$ Corresponding author: S. Sinharoy: E-mail: ssinharoy@nipgr.ac.in

Funding: This work was supported by a core research grant from National Institute of Plant Genome Research and Ramalingwaswami, Department of Biotechnology, Ministry of Science and Technology Re-entry grant (BT/RLF/Re-entry/41/2013).

The $\boldsymbol{e}$-Xtra logo stands for "electronic extra" and indicates that three supplementary figures and one supplementary table are published online.

○ 2019 The American Phytopathological Society symbiotic interaction with a Mesorhizobium sp., chickpea can be cultivated in a sustainable way (Jain et al. 2013; Varshney et al. 2013). Research on nodule development has been centered upon model legumes Medicago truncatula and Lotus japonicus. Today, model legumes are in the forefront of legume biology in terms of both available knowledge and resources. The only disadvantage is that model legumes are not crop species. In spite of being the most important grain legume in tropical and subtropical countries (Jukanti et al. 2012), the literature on chickpea nodule development is scarce. Genome sequencing and the establishment of transcriptomic and proteomic resources have laid the pillars for making chickpea a model among crop legumes (Jain et al. 2013; Pandey et al. 2018; Ramalingam et al. 2015; Varshney et al. 2013). Further, seed-to-seed generation time in chickpea is short, between 85 and 100 days, which makes it even more suitable for future studies (Upadhyaya et al. 2007).

Chickpea belongs to the inverted repeat-lacking clade (IRLC), which diverged from model legume Medicago approximately 10 to 20 million years ago (Jain et al. 2013; Varshney et al. 2013). IRLC legumes develop indeterminate nodules, in which a gradient of cells at different stages of development can be seen from the distal to the proximal part of the nodule. A persistent meristem (zone I) is present at the distal end of the nodule. Bacterial endocytosis and colonization take place in the postmeristematic cells of the infection zone (zone II), in which plant membrane-bound bacterial units are formed. These units are called symbiosome (Roth and Stacey 1989). The rhizobia inside the symbiosomes are called bacteroids. The bacteroids divide inside the symbiosome and gradually colonize the whole cell. In the nitrogen-fixation zone (zone III), bacteroid differentiation is terminated, ammonium assimilation genes are repressed, and nitrogen-fixation genes are induced. In the nitrogen-fixation zone, the symbiosome are considered as an ammonium-exporting organelle (Oldroyd 2013; Udvardi and Poole 2013).

Terminally differentiated, enlarged bacteroids with different morphotypes are a typical feature of the IRLC legumes. The major determining factor behind these irreversibly differentiated bacteroids is nodule-specific cysteine-rich (NCR) peptides (Montiel et al. 2016, 2017). The molecular mechanism of NCR peptide-regulated endoreduplication of the symbiont genome has been worked out in model legume Medicago. Medicago genome encodes more than 700 NCR genes (Mergaert et al. 2003; Young et al. 2011). At least 138 NCR peptides get processed in the endoplasmic reticulum (ER) and targeted toward symbiosomes (Durgo et al. 2015; Wang et al. 2010). NCR 
peptides force endoreduplication of the symbiont genome. As a result, the bacteria (now bacteroids) lose their ability to divide and regrow on culture media, but their size increases up to approximately 10 fold (Mergaert et al. 2006; Sinharoy et al. 2013; Young et al. 2011). The NCR gene family is evolved in Medicago spp. by a recent local gene duplication (Alunni et al. 2007). NCR genes have been identified in several IRLC legumes, including chickpea (Kant et al. 2016; Montiel et al. 2016, 2017). The number of NCR genes among different IRLC legumes varies greatly. This results in different morphotypes of bacteroids in different legumes, such as swollen/spherical, elongated, and elongated-branched (Montiel et al. 2017). Mesorhizobium TAL620-induced nodules in chickpea express only 63 $N C R$ genes, while its bacteroid endoreduplicated up to four fold (Kant et al. 2016; Montiel et al. 2017). Chickpea and Medicago NCRs share less than $80 \%$ identity. Chickpea NCR peptides have more identity with Glycyrrhiza uralensis, Onobrychis vicifolia, and Astragalus canadensis, while phylogenetically chickpea is closer to Medicago (Montiel et al. 2016, 2017). Chickpea swollen or spherical bacteroids are basal to the evolution of NCR-guided morphogenesis (Montiel et al. 2017). In contrast to chickpea, Medicago has more than 700 NCR genes (Young et al. 2011). Bacteroids in Medicago nodules are elongated-branched, which depict an advance stage of this trait. Interestingly, this morphogenesis of bacteroids and the genome endoreduplication is thought to determine the efficiency of nitrogen fixation in respective legumes (Oono and Denison 2010). Thus, comparative investigation of nodule development in chickpea and Medicago will enhance our knowledge on the evolutionary link between variable nitrogen-fixation efficiencies among different legumes.

An efficient hairy-root transformation protocol is an indispensable tool to understand nodule biology, enabling us to study the localization of any protein (fluorescent tag), activities of promoters ( $\beta$-glucuronidase $[G U S]$ fusion), and the effects of overexpression or knockdown of certain genes. We have undertaken an effort to establish hairy-root transformation in chickpea and study nodule development. Unlike Agrobacterium tumefaciens, A. rhizogenes generates transformed roots from the site of infection. A. rhizogenes contains root locus (rol) genes in the Ri plasmid, which promotes the formation of genetically transformed adventitious hairy roots. A. rhizogenes carrying a recombinant $\mathrm{Ri}$ plasmid can generate composite plants. These plants contain untransformed shoot and transformed root (Stougaard et al. 1987). When A. rhizogenes strain additionally carrying a gene of interest in a binary vector is used for hairy-root transformation, a certain percentage of roots also obtained the binary vector and those roots are called cotransformed roots. Both overexpression and downregulation of a specific gene can be achieved by these cotransformed roots (Limpens et al. 2004; Sinharoy and DasGupta 2009; Sinharoy et al. 2015). Recently, it has been reported that CRISPR/Cas9mediated gene knockout is also possible in hairy roots (Cai et al. 2015; Ron et al. 2014; Wang et al. 2016). To date, all the successful protocols describing hairy-root transformation in legumes have shown the transformed roots to be biologically similar to untransformed roots, with no difference in nodule development (Boisson-Dernier et al. 2001; Bonaldi et al. 2010; Brijwal and Tamta 2015; Estrada-Navarrete et al. 2006; Habibi et al. 2016; Imanishi et al. 2011; Kereszt et al. 2007; Limpens et al. 2004; Quandt et al. 1993; Sinharoy et al. 2009; Stiller et al. 1997; Stougaard et al. 1987; Thilip et al. 2015; Thwe et al. 2016; Van-deVelde et al. 2003). A. rhizogenes-mediated hairy-root transformation is more efficient and less time-consuming than stable transformation. Thus, it serves as an alternative method for functional validation of genes. Here, we are reporting an efficient protocol for hairy-root transformation in chickpea. We have developed both in-vitro and ex-vitro protocols. We have used four different Mesorhizobium strains to follow nodule initiation and developmental programs and evaluated the nitrogen-fixation efficiency. We have also checked the localization of several subcellular markers in transformed chickpea roots and nodules. Additionally, we have shown that different strains of Mesorhizobium give rise to mature bacteroids with different shapes. The efficiency of nitrogen fixation is lower when the shape is elliptical instead of spherical.

\section{RESULTS}

\section{Hairy-root transformation of chickpea.}

We used Agrobacterium rhizogenes strains R1000 (Quandt et al. 1993), ARqua1 (Quandt et al. 1993), and MSU440 (Sonti et al. 1995) for hairy-root transformation. All three strains were successful to generate hairy roots (Supplementary Table S1). For detailed characterization, we used a low-virulence strain, A. rhizogenes ARqual (Quandt et al. 1993). Dicotyledonous plants can be transformed using both in-vitro (tissue culturebased) and ex-vitro (without tissue culture) protocols (Collier et al. 2005; Sinharoy et al. 2015). We attempted both methods. For in-vitro transformation, chickpea seedlings were infected either by cutting 1 to $1.5 \mathrm{~cm}$ of the radicle and scraping it in an A. rhizogenes lawn culture or using a needle containing A. rhizogenes to make a small wound at the hypocotyl region. An overview of the methods is given in Figure 1. In both cases, transformed roots began to emerge from the infected region 14 to 15 days after infection (dai) (Fig. 1, step-Ia). In the case of needle-mediated $A$. rhizogenes infection, the original nontransformed roots were removed from the plant when transformed roots started emerging. These plants were transferred to kanamycin-containing selection medium to increase the efficiency of the transformation. We tried two different concentration of kanamycin $(50$ and $25 \mu \mathrm{g} / \mathrm{ml})$. The plants were maintained in the antibiotic-containing medium for 14 to 15 days for antibiotic selection. All the roots became black and plants died within two weeks when $50 \mu \mathrm{g}$ of kanamycin per milliliter was used (20 of 20 plants died). In contrast, the transgenic roots grew normally in the presence of $25 \mu \mathrm{g}$ of kanamycin per milliliter. The shoots of composite plants had no difference in morphology with their nontransgenic counterparts (Fig. 1, step IIa). The transformed roots exhibited characteristics of plagiotropic growth. The transformation frequency was determined using either the Cauliflower mosaic virus $35 \mathrm{~S}$ promoter or Arabidopsis ubiquitin 10 (AtUBQ10) promoterdriven expression of the DsRed fluorescent protein (Fig. 1, step IIIa). pCAMBIA2301 vector was used for the determination of p35S-driven expression of gusA gene. In pCAMBIA2301, the gusA gene contains an intron. The glucuronidase activity by the chickpea roots confirmed proper integration of the transformed gene. The $p K G W$-Red-Root vector was used for the determination of $A t U B Q 10$ driven DsRed expression (Table 1). Both in vitro transformation methods either by cutting or injecting showed a similar frequency of cotransformed roots (Table 1). Usually, we obtained a slightly greater frequency of transformed roots after antibiotic selection (Table $1.53 \pm 23$ with antibiotic over $49 \pm 20$ without antibiotic) using the same vector in same chickpea genotype (BDG256). Plants generated by in vitro methods were transferred to the substrate (a mixer of 3:1 vermiculite and fireclay balls, leca) 14 to 15 dai (in case of without antibiotic treatment). Nonfluorescent roots were removed from the plants at this point (Materials and Methods section). Nodules were observed in these transformed roots within 10 days postinoculation (dpi) with Mesorhizobium (Fig. 1 Step IVa). The cotransformed roots develop healthy and active nodules which can fix nitrogen efficiently $\left(7.6 \pm 3\right.$ nmole ethylene plant ${ }^{-1}$ hour $\left.^{-1}\right)$. 
Ex-vitro composite plant generation is a rapid, efficient, simple, and low-cost method for producing composite plants without tissue culture (Collier et al. 2005; Sinharoy et al. 2015). The steps for ex vitro transformation are shown on the right-hand side of Figure 1. For ex vitro transformation, 25-30 days old apical stem tissue of young branches were cut and dipped in the A. rhizogenes culture and transferred to the substrate (Fig. 1 Step1b). Further, the plants were maintained in a humid chamber for 30 days to promote root production in presence of full nitrogen fertilization regime. Both transformed and adventitious root production were observed by 20 dai. The transformed roots were screened based on dsRed fluorescence (Fig. 1 step IIb). At this point, the substrate containing plants were washed thoroughly with distilled water, and transferred to a new pot and maintained under nitrogen free condition. After 2-3 days the plants were inoculated with Mesorhizobium culture for root nodule development, and nodules were noticed within 10 dpi (Fig. 1 step IIIb). Ex vitro transformation protocol showed slightly lower transformation efficiency compared with any of the in vitro transformation protocols (Table 1).

We have tested this protocol in different chickpea ecotypes. A list of different cultivars of chickpea from different origin, for which we successfully tested our transformation protocol, has been given in Table 1. Both in vitro and ex vitro methods had comparable transformation efficiency. While we obtained greater transformation efficiency in $B D G 256$, and 'local' variety (above 50\%), ICC4958 and ICC 8261 had a lower efficiency. In summary, using our protocols hairy roots can be generated in several different ecotypes of chickpea.

Expression of different subcellular markers in transformed hairy roots and nodules of chickpea.

To test the activity of transgenes transformed following our protocol we employed already known markers for their

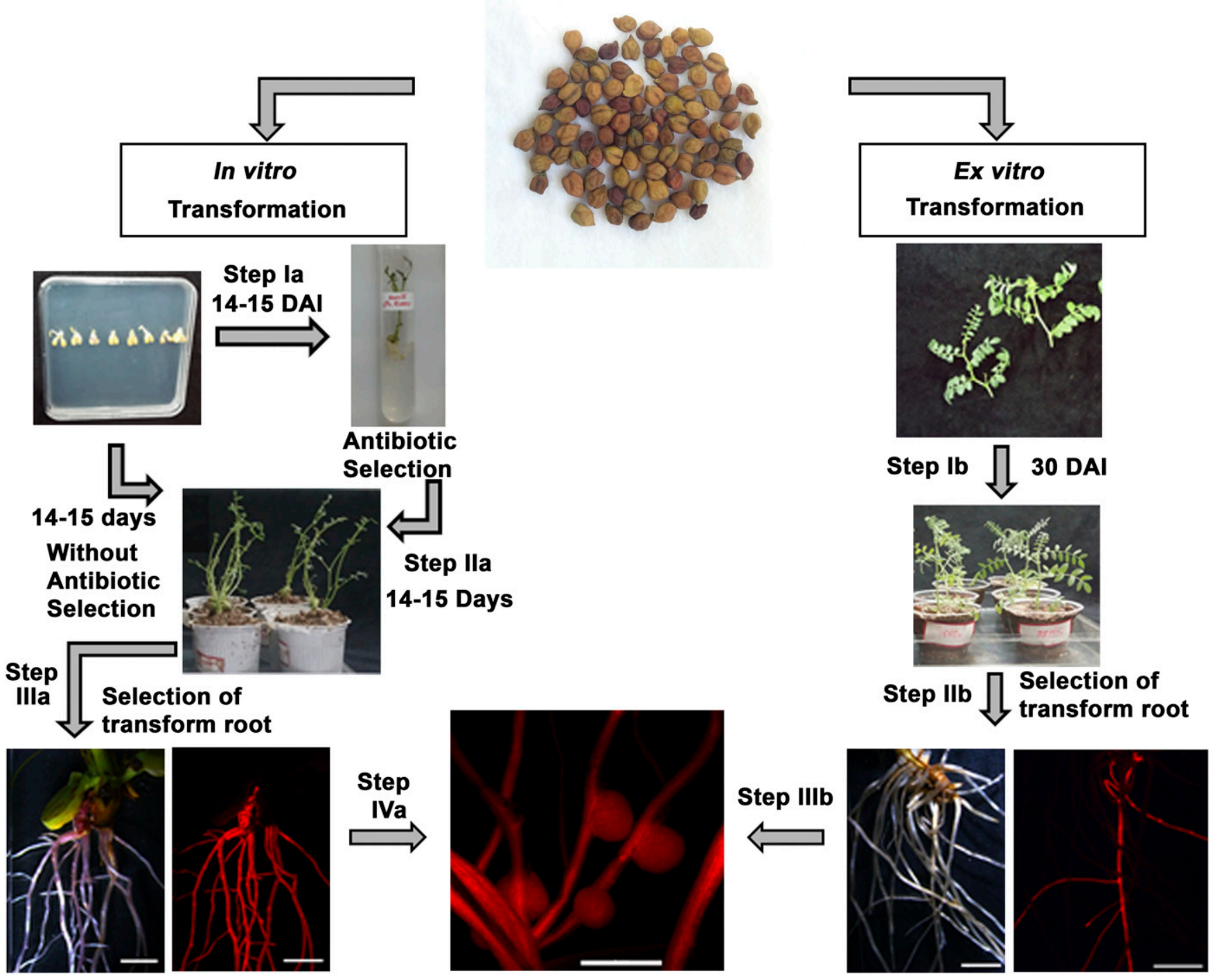

Fig. 1. Agrobacterium rhizogenes induced hairy roots in chickpea. For in-vitro transformation, germinated seedlings were infected with Agrobacterium rhizogenes and were plated on Fahraeus medium. At 14 to 15 days after infection, hairy roots were seen and the composite plants were transferred in selective antibiotics (step Ia). After 14 to 15 days, the plants were transferred to growing substrate (step IIa). Alternatively, after 14 to 15 dai, plants were directly transferred to growing substrate. Transformed roots were screened under the red channel of the stereomicroscope (step IIIa). Composite plants were inoculated with Mesorhizobium ciceri CC1192 after 22 to 23 days (step IVa). For ex vitro transformation, the wounded portion was inoculated with Agrobacterium rhizogenes. At 30 days after infection, hairy roots were seen (step Ib) and transformed roots were screened under the red channel of the stereomicroscope (step IIb). The composite plants were inoculated with M. ciceri CC1192 for nodulation (step IIIb). The transformed root pictures were taken under the stereomicroscope either under bright field or under the red channel. 
subcellular localization in chickpea root and nodules. These markers were already published for either Arabidopsis thaliana (At) (model plant), or Medicago truncatula (Mt) (model legume) (Nelson et al. 2007; Ivanov and Harrison 2014). We expressed some of these markers in hairy roots and nodules of chickpea (Supplementary Fig. S1). A construct created by fusing the signal peptide of AtWAK2 (Arabidopsis thaliana wall-associated kinase 2) at the N-terminus of a mCherry sequence which also contained endoplasmic reticulum (ER) retention signal HDEL at the C-terminus, was used as ER marker. This $m$ Cherry was under AtUBQ10 promoter (He et al. 1999). An extensive characteristic tubular and sheet-like ER network was seen throughout the cytoplasm of chickpea root epidermal cells. As expected, ER network around the nucleus was more uniform. The mitochondrial marker was created by adding the first 29 amino acids of Saccharomyces cerevisiae cytochrome c oxidase IV with a $m C h e r r y$ sequence under $p A t U B Q 10$ (Kohler et al. 1997). Typical small and round mitochondria were present in high copy numbers in every cell in chickpea hairy root epidermis. The mitochondria were generally clustered in the periphery of the cells, and around the nucleus. A similar result was obtained earlier in Medicago (Ivanov and Harrison 2014). We have used $p A t U B Q 10$ driven $m C h e r r y$ fused with Lifeact, a 17 amino acid peptide which binds filamentous actin as the actin filament marker (Riedl et al. 2008). In root epidermal cells, we noticed extensive filamentous actin networks. The marker for peroxisome was created by fusing SKL signal peptide of AtPTS1 to the C-terminal of mCherry (Reumann 2004). Innumerable peroxisomes were seen in the cells of chickpea root epidermis. Unlike mitochondria, peroxisomes were scattered all around the cells. To monitor the localization of apoplasts, we used the $p A t U B Q 10$-driven expression of Medicago blue copper protein's $(M t B C P 1) 23$ amino acid signal peptide (BCPsp) fused to $m$ Cherry (Pumplin and Harrison 2009). MtBCP1 signal peptide drives the routing of mCherry to apoplasts, as was also seen in Medicago before (Ivanov and Harrison 2014). From the MtBCP1sp-mCherry localization, it is clear that the epidermal cells are connected through apoplastic connection. Additionally, we used the $p 35 S$ promoterdriven expression of a plasma membrane aquaporin (PIP2a) fused to cyan fluorescent protein (CFP) (Cutler et al. 2000). We noticed the uniform labeling of CFP along the surface of the cell. A marker created by fusing plasmodesmata-located protein 1 gene $(P D L P 1)$ with $m$ Cherry at the $\mathrm{N}$ terminus under $p A t U B Q 10$ was used to visualize the cytoplasmic connections between the cells (Thompson and Wolniak 2008). A crosssection of chickpea root showed the symplastic connections between the cortical cells. The Golgi body marker was created by fusing the N-terminal 49 amino acids of GmMAN1 to the $\mathrm{N}$ terminus of $m$ Cherry (Saint-Jore-Dupas et al. 2006). The Golgi apparatus were scattered throughout the cytoplasm in the chickpea root epidermal cell. To check the hormone responsiveness in these transformed roots, we used a construct created by fusing a nuclear localization signal $(N L S)$ at the Cterminus of GFP under auxin-responsive synthetic DR5 promoter (DR5-GFP-NLS) (Suzaki et al. 2013). We noticed high GFP expression around the proliferating lateral root primordial cells, but GFP fluorescence was not observed in the mature root cortex. In summary, by using eight different subcellular markers under both $35 S$ and the AtUBQ10 promoter and the DR5-GFP construct, we confirmed the normal physiological functioning of these transformed roots.

The transgenic hairy roots also showed efficient nodule development (Fig. 1). After the bacterial endocytosis in the postmitotic cells, bacteroids multiply and rapidly fill up the entire cell. The peribacteroid membrane is a plant-derived membrane. Hence, the division of bacteroids accompanies a huge expansion of the elements of the host cell membrane. Several parallel evidences suggest that membrane trafficking toward symbiosomes increases significantly during this phase (Gavrin et al. 2017). Symbiosomes in Medicago spp. have a unique mosaic identity with plasma membrane syntaxin SYP132 and endomembrane marker (regulatory small GTPases of the Rab family) Rab7 (Limpens et al. 2009). This suggests that, under certain circumstances, established markers may behave differently inside the infected nodule cells. To demonstrate the utility of this protocol, we used three subcellular markers (peroxisome, ER, and Golgi) to check their localization inside nodule cells. Peroxisomes are organelles that play key roles in plant cell metabolism (Hu et al. 2012). The central infected nodule tissue is surrounded by three layers of uninfected peripheral tissues, namely, from inside to outside, the nodule parenchyma, endodermis, and cortex (Xiao et al. 2014). We noticed the presence of a higher number of peroxisomes in the nodule cortex around the vascular tissue (Fig. 2A). The number of peroxisomes was low in nodule parenchyma and endodermis (Fig. 2A), but the density of peroxisomes was more or less similar in all infected zones (Fig. 2B and C). The Golgi apparatus (cis-Golgi) were noticed everywhere inside the infected cells surrounding the symbiosomes (Fig. 2D). We failed

Table 1. Agrobacterium rhizogenes ARqual-mediated transformation of different chickpea ecotypes with binary vector $p K G W$-Red-Root and $p C A M B I A 2301$

\begin{tabular}{|c|c|c|c|c|c|c|c|}
\hline \multirow[b]{3}{*}{ Genotype } & \multirow[b]{3}{*}{ Region } & \multicolumn{3}{|c|}{$\begin{array}{c}\text { Method of transformation (fraction of } \\
\text { transformed plants) }\end{array}$} & \multicolumn{3}{|c|}{$\begin{array}{c}\text { DsRed- or GUS-positive hairy roots per } \\
\text { cotransformed plant }{ }^{\mathbf{b}}(\%)\end{array}$} \\
\hline & & \multicolumn{2}{|c|}{ In vitro } & \multirow[b]{2}{*}{ Ex vitro } & \multicolumn{2}{|c|}{ In vitro } & \multirow[b]{2}{*}{ Ex vitro } \\
\hline & & Cut & Inject & & Cut & Inject & \\
\hline ICC $4958^{1 \mathrm{c}}$ & India & $16 / 20$ & ND & ND & $26 \pm 9$ & ND & ND \\
\hline ICC $17258^{1 \mathrm{c}}$ & India & $20 / 20$ & ND & ND & $40 \pm 17$ & ND & ND \\
\hline $\mathrm{ICC} 1885^{1 \mathrm{c}}$ & India & $18 / 20$ & ND & ND & $37 \pm 16$ & ND & ND \\
\hline ICC $8261^{2 \mathrm{c}}$ & Turkey & $9 / 20$ & ND & ND & $27 \pm 7$ & ND & ND \\
\hline Local Variety ${ }^{1 \mathrm{c}}$ & India & $35 / 35$ & $31 / 35$ & $34 / 35$ & $50 \pm 21^{*}$ & $51 \pm 21 *$ & $40 \pm 17$ \\
\hline BDG265 ${ }^{1 \mathrm{c}}$ & India & $19 / 20$ & $17 / 20$ & $14 / 20$ & $49 \pm 20$ & $40 \pm 16$ & $38 \pm 16$ \\
\hline BDG256 $6^{1 \mathrm{c}}$ & India & $21 / 25$ & ND & ND & $53 \pm 23^{*}$ & ND & ND \\
\hline BDG256 $6^{1 \mathrm{~d}}$ & India & $10 / 10$ & ND & ND & $40 \pm 17$ & ND & ND \\
\hline
\end{tabular}

${ }^{a}$ Fraction of cotransformed composite plants were determined based on either DsRed fluorescence or $\beta$-glucuronidase positive hairy roots. ND $=$ not determined.

${ }^{\mathrm{b}}$ Four weeks after infection, the fraction of cotransformed roots were determined. Asterisks $(*)$ indicate values that show the percentage after antibiotic selection.

${ }^{c}$ Numbers of cotransformed hairy roots were counted based on DsRed fluorescence. A superscript 1 following the genotype name indicates Desi and a superscript 2 indicates Kabuli variety.

${ }^{\mathrm{d}}$ Numbers of cotransformed hairy roots were counted based on $\beta$-glucuronidase (GUS) positive hairy roots per plant. 
to detect any Golgi apparatus surrounding the infection thread (Fig. 2D). ER also shows a similar localization pattern to the Golgi, close to the symbiosomes (Fig. 2E). Additionally, we were able to detect ER around the infection thread (Fig. 2F).

\section{Evaluating the symbiotic potential} of different Mesorhizobium strains.

An efficient laboratory strain is a prerequisite to study nodule development. We examined several different $M$. ciceri strains, originating from different sources, to evaluate their potential for healthy nodule development and $\mathrm{N}_{2}$ fixation efficiency. M. ciceri CC1192 is an Australian isolate used as a commercial inoculant, and, recently, the complete genome sequence has been published (Haskett et al. 2016). Mesorhizobium ciceri IC-59 was isolated by ICRISAT (International Crops Research Institute for the Semi-Arid Tropics, Hyderabad, India) (Esfahani et al. 2014; Rupela and Sudarshana 1990) and is being used for different field trials (Esfahani et al. 2014). M. ciceri TAL620 was used for studies in the past (Chandra and Pareek 1987) and recently has been used for the transcriptome sequencing of chickpea root nodules (Kant et al. 2016). Our own isolation effort from the experimental garden of the $\mathrm{Na}$ tional Institute of Plant Genome Research (NIPGR), New Delhi, India, has resulted in the culturing of NIPGR isolate 7 or NI-7. Chickpea plants with healthy pink nodules were collected from the experimental garden. The pink nodules were surfacesterilized, and rhizobia were isolated from the nodules (details below). The $16 \mathrm{~S}$ rDNA sequence of the NI-7 strain has been submitted to the National Center for Biotechnology Information (NCBI) database (MH517450). Interestingly, NI-7 shows the highest similarity with Mesorhizobium tianshanense. M. tianshanense nodulating Cicer arietinum and Cicer canariense have already been reported (Armas-Capote et al. 2014; Rivas et al. 2007). We generated nodules by inoculation of all four above-mentioned Mesorhizobium strains (Supplementary Fig. S2). All four strains were able to initiate nodules by 6 dpi (bump formation). Numerous small white round-shaped nodules were observed by $10 \mathrm{dpi}$. At $15 \mathrm{dpi}$, nodules were pink (due to the expression of leghemoglobin) in CC1192, IC59, and NI-7 but remained white in TAL620. When followed further, all four nodules become pink by 21 dpi. By 28 and 35 dpi, CC1192, IC59, and NI-7 nodules showed a similar developmental fate by becoming elongated and cylindrical, while TAL620 nodules were comparably smaller and pale pink. Senescence zones, a typical feature of indeterminate nodules, started appearing by 35 dpi in most of the nodules. In TAL620 nodules, the senescence zone was visible even from 28 dpi. This suggests that TAL620 is a comparably inefficient strain for chickpea nodule development. We performed acetylene reduction assays (ARA) at 21 and $35 \mathrm{dpi}$, to determine the nitrogen-fixation efficiency of these strains. CC1192 showed the highest ARA, followed by NI-7, IC59, and TAL620 at both timepoints (Fig. 3A). Both NI7 and IC59 show sa ignificantly low ARA when compared with CC1192. But TAL620 showed a significantly low ARA compared with CC1192, NI-7, and IC59 at both timepoints. Further, we determined the biomass of the full plants at 35 dpi, to understand how nodule development by different Mesorhizobium strains affects overall plant growth. Based on biomass, TAL620-inoculated plants showed significant growth retardation and IC59-inoculated plants showed slight
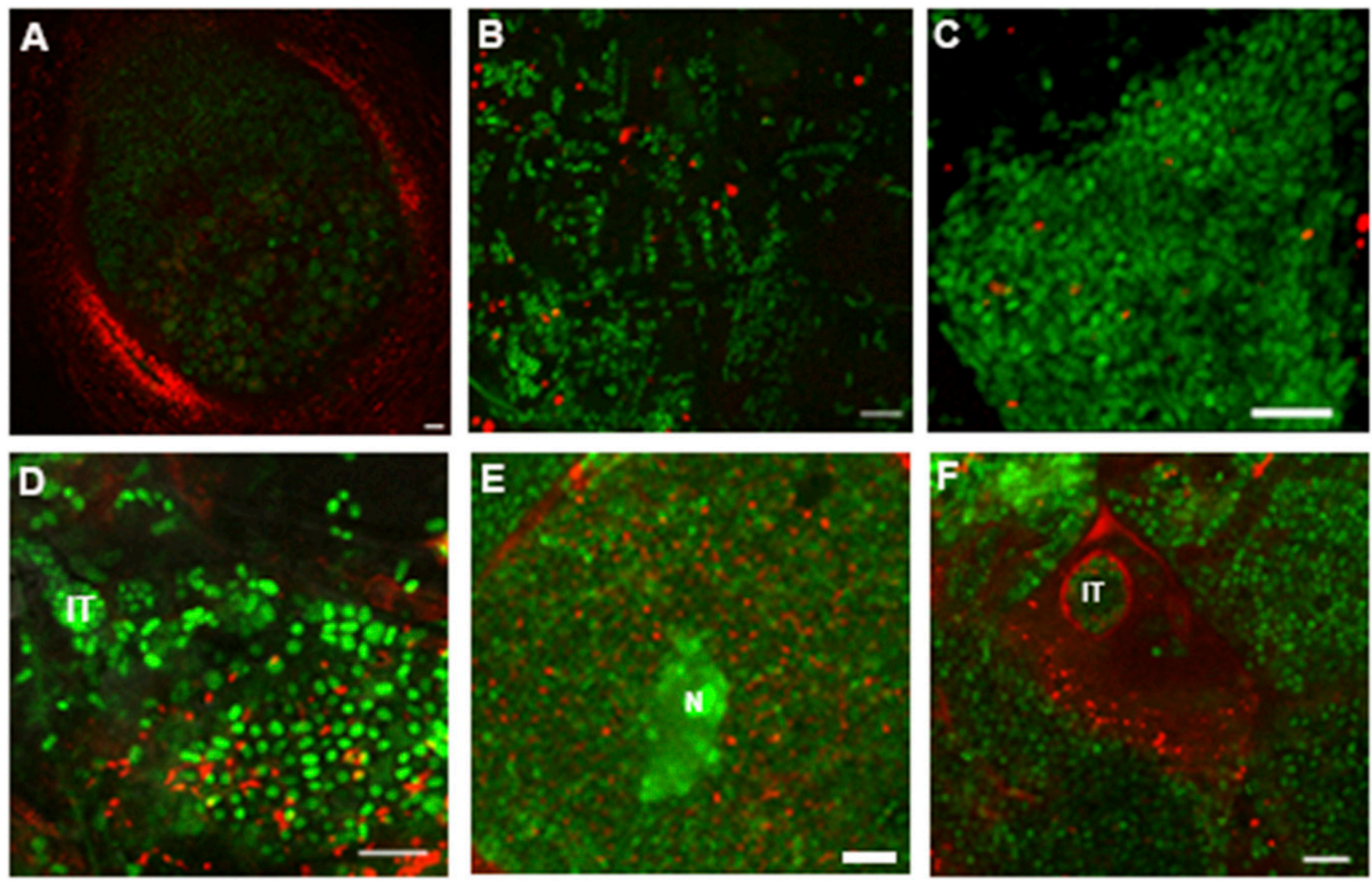

Fig. 2. Localization of different subcellular protein markers in transgenic chickpea nodules. A to $\mathbf{F}$, Transformed nodules were hand-sectioned and were stained with SYTO13 (DNA, green). A to C, mCherry-SKL showing localization in the peroxisome whole nodule (A), invasion zone (B), and nitrogen-fixation zone (C). D, MAN49-mCherry localization in Golgi bodies in the nitrogen-fixation zone. $\mathbf{E}$ and $\mathbf{F}$, mCherry-HDEL localization in the endoplasmic reticulum in the nitrogen-fixation zone of transgenic chickpea nodules induced by Mesorhizobium ciceri CC1192. $\mathrm{N}=$ nucleus and IT $=$ infection thread. Scale bars in A = $50 \mu \mathrm{m}$ and $\mathrm{B}$ to $\mathrm{F}=5 \mu \mathrm{m}$. 
growth retardation compared with $\mathrm{CC} 1192$ inoculated plants (Supplementary Fig. S3). Taken together, our data show that CC1192 is the most efficient strain for chickpea, followed by NI-7. Further, we have used SYTO dyes to stain the nitrogen-fixation zone of these chickpea nodules at $21 \mathrm{dpi}$. Interestingly, we found small spherical symbiosomes inside CC1192-, IC59-, and NI-7-generated nodules (Fig. 3B to D), whereas in the case of TAL620 the symbiosomes were small and elliptical (Fig. 3E). Our result shows that elliptical symbiosomes are associated with low ARA. Acidification of symbiosome space is crucial for functional nitrogen fixation. LysoTracker DND189 has been successfully used in Medicago spp. for in-planta detection of peribacteriod space (PBS, also called symbiosome space) acidification (Pierre et al. 2013). We then asked whether there is any correlation between the PBS acidity and ARA by the above-mentioned strains. We used $\mathrm{pH}-$ sensitive dyes DND189 to stain the most efficient (CC1192) and the least efficient (TAL620) Mesorhizobium-induced nodules. DND189 is a weak base linked with a fluorophore. It gets protonated in acidic organelles and is retained in the membranes of those organelles. The biggest advantage of DND189 over most of the lysotrackers is that it is almost nonfluorescent except when inside acidic compartments (Lopez et al. 2005). DND189 starts fluorescing at a $\mathrm{pH} \leq 5.2$ and reaches an optimal emission between $\mathrm{pH} 4$ and 5. We used DND189 in combination with SYTO82/PI (propidium iodide) to check the acidity of chickpea symbiosome space. In CC1192, DND189 was accumulated in the PBS and we observed the clear spherical shape of the acidic zone (PBS) (Fig. 4A and B). The bacterial nucleic acid showed clear red staining when it was counterstained with SYTO82 (Fig. 4B). There was some acidity in the PBS of the symbiosomes made by strain TAL620, but we rarely obtained a clear demarcation of PBS boundary when stained with DND189 (Fig. 4C). To test the viability of bacteria inside TAL620-induced nodules, we used PI staining (Haag et al. 2011). Live bacteria with intact cytoplasmic membranes would be stained by membrane-permeable SYTO dye, while dead bacteria with degraded cytoplasmic membranes would be stained by membrane-impermeable PI. When TAL620-induced nodules were stained with PI, the nucleic acid in most of the samples did not take up the stain. Interestingly, the few instances where sporadic symbiosomes took up the stain, they were spherical (Fig. 4D). The frequency of occurrence of such zones inside the nodules is scarce, whereas SYTO dye shows live bacteroids inside TAL620-induced nodules (Fig. 3D). Hence, from our observation, it appears that DND189 is accumulated less specifically in the PBS of TAL620-induced symbiosomes, indicative of less acidity.

\section{DISCUSSION}

Unlike model legumes, nodule development studies in chickpea are limited. Nodule development in chickpea and
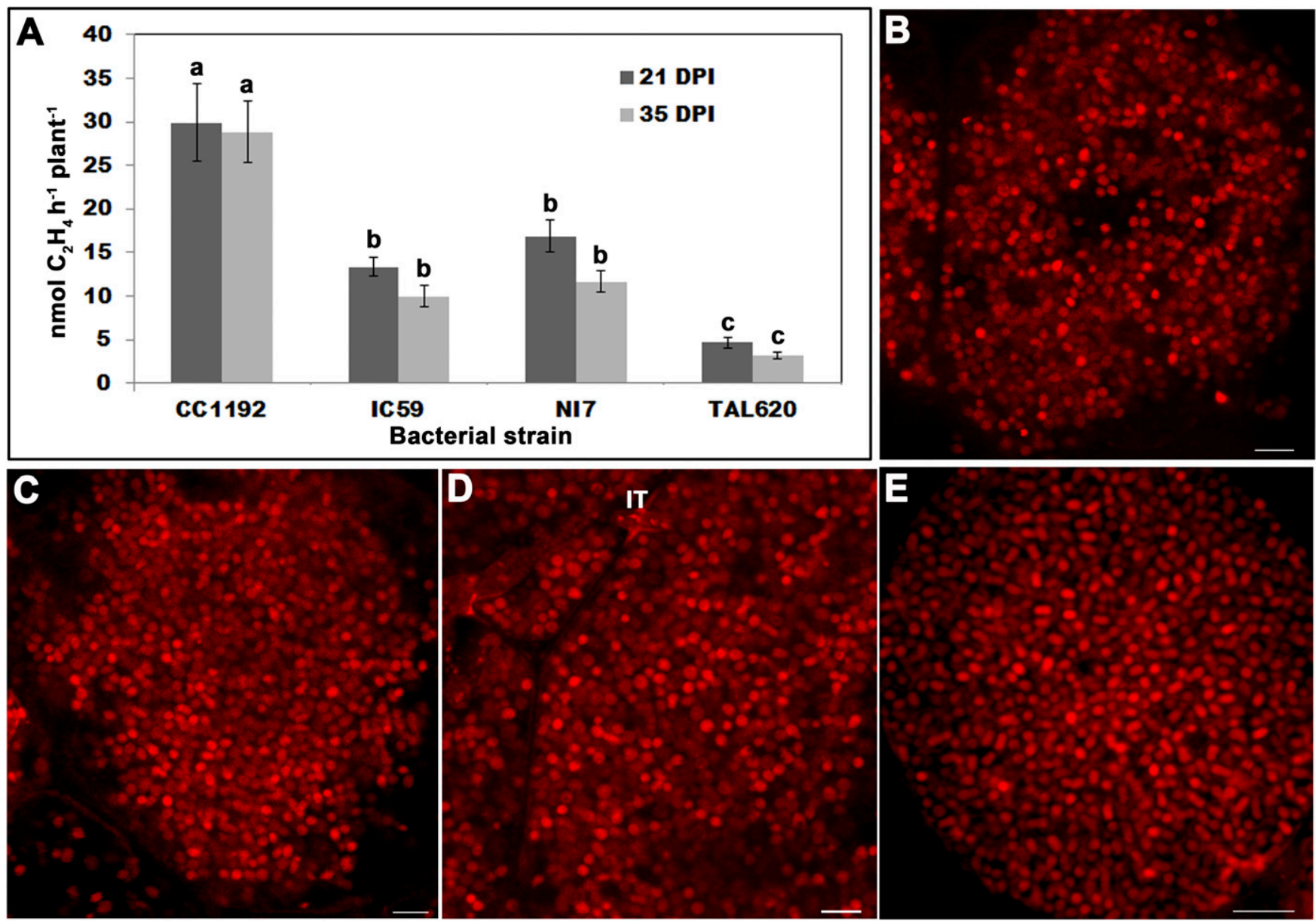

Fig. 3. Characterization of chickpea nodules induced by different Mesorhizobium strains. A, Acetylene reduction activity with M. ciceri CC1192, M. ciceri IC59, Mesorhizobium sp. strain NI-7, and M. ciceri TAL620 induced nodules at 21 and 35 days postinoculation (dpi). Data presented are the means \pm standard error of mean per plant from four independent experiments (with five plants from each experiment). Data with different letters reveal significant differences as measured by a $t$ test $(P \leq 0.05)$. B to E, Chickpea nodules ( $21 \mathrm{dpi})$ were hand-sliced and were stained with SYTO82. M. ciceri CC1192 (B), M. ciceri IC59 (C), Mesorhizobium sp. strain NI-7 (D), and M. ciceri TAL620 (E) induced nodules in BDG256 chickpea ecotype. IT $=$ infection thread. Scale bars in A to D $=5 \mu \mathrm{m}$. 
Medicago spp. follow a similar course. Hence, the knowledge on Medicago nodule development holds true for many aspects of nodule development in chickpea. Nonetheless, differentiation of bacteroids in both systems shows major dissimilarity. Bacteroid differentiation takes place in the invasion zone of both Medicago and chickpea nodules. Bacteroids inside Medicago nodules endoreduplicate up to 24-fold, whereas a maximum of fourfold endoreduplication is observed in chickpea (Montiel et al. 2017). Certain NCR genes (dnf4-NCR211 and dnf7-NCR169) are indispensable for nitrogen fixation in Medicago spp. (Horvath et al. 2015; Kim et al. 2015). Recently, it has been shown that two $N C R$, nitrogen-fixation specificity genes (NFS1 and 2) also function as negative regulators of symbiont persistence (Wang et al. 2017; Yang et al. 2017). Such a specific role of a few NCR peptides amid overall redundancy among the members of this family suggests complex regulation behind the evolution of terminal differentiation of bacteroids. Also, the presence of a much lower number of NCR genes and the absence of the symbiotically essential NCRs in the chickpea genome suggest major differences in the molecular regulation of bacteroid differentiation (Montiel et al. 2017).

The recalcitrance of chickpea toward transformation and its low regeneration efficiency is a bottleneck at this moment (Indurker et al. 2007; Varshney et al. 2010). For root biologists, hairy-root transformation is an easy alternative to stable lines. The cotransformed roots can be used for overexpression, knockdown, or CRISPR/Cas9-mediated deletion of a gene of interest (Limpens et al. 2009; Ron et al. 2014). To date, most of the literature on RNS in model legumes uses hairy-root transformation. Two preliminary reports, by Altinkut et al. (1997) and Khawar and Ozcan, (2004), have previously described hairy-root transformation using chickpea. Those reports are preliminary without cotransformation efficiency calculation and, also, nodule development by the cotransformed roots had not been evaluated. Here, we are reporting an efficient transformation protocol, showing 26 to $53 \%$ cotransformed root generation and the normal physiological functioning of the cotransformed roots, by using eight different subcellular markers and auxin-responsive DR5-GFP construct. Further, the nodule development and symbiotic nitrogen fixation by the cotransformed roots had been evaluated (Figs. 1 and 2). The cotransformation efficiency in the BDG256 ecotype is $49 \pm 20$ without antibiotic whereas, with antibiotic, it is $53 \pm 23$ (Table 1). We only observed a mild increase in the transformation frequency when antibiotic selection is used. Hence, the antibiotic selection step can be omitted during composite plant generation in chickpea. The transformation efficiency of the model legume ranges around 60 to $70 \%$. On the other hand, the transformation efficiency of the large-seeded grain legumes soybean, Vigna spp., and pea varies greatly between 20 and $80 \%$ (Sinharoy et al. 2015). According to our protocol, the transformation efficiency of chickpea varies greatly between ecotypes, ranging between 26 and 53\% (Table 1). This is comparable to other large-seeded grain legumes. These transformed roots develop healthy and active nodules (Fig. 1) that can fix nitrogen efficiently. We have tested our protocol using nine different constructs carrying different transgenes, and all of them showing an expected pattern and subcellular localization (Fig. 2).

Our data show that peroxisomes are enriched around the vascular bundle in the nodule cortex (Fig. 2). Peroxisomes play a major role in ureide transport inside the determinant nodules of soybean (Hanks et al. 1981). The role of peroxisomes in amide transporting nodules of temperate legumes is not clear. Scavenging of toxic $\mathrm{H}_{2} \mathrm{O}_{2}$ around the nodule cortex could be one possibility. Presence of active peroxisomes has been reported also in the meristem and the invasion zones of pea nodules (Borucki 2007). On the contrary, we have noticed a higher number of peroxisomes in the nodule cortex (Fig. 2A). Discrimination between active and inactive peroxisomes was beyond the limits of the present study. Our observation demands further studies on the significance of peroxisome accumulation around the nodule cortex of temperate legumes like chickpea. In Medicago spp., the ER apparatus is assembled within the epidermal cells around an area where the future infection thread would penetrate, even before the actual penetrance (Genre et al. 2005). The localization of ER around the infection threads in chickpea nodules indicates similar organization (Fig. 2F). ER-medicated trafficking is important during endocytosis of bacteroids. Normally, proteins of the exocytosis pathway go from the ER to the membrane through the Golgi bodies (Gavrin et al. 2017; Ivanov et al. 2012). Surprisingly, we did not find Golgi bodies around the infection threads. The significance of selective concentration of ERs in combination with the absence of Golgi bodies around the infection threads is not clear.

The efficiency of nitrogen fixation differs significantly, depending on bacterial strains. A systematic effort to evaluate the behavior of different Mesorhizobium strains during chickpea nodule development has not been given to date. Our study highlights a striking difference of symbiotic performances between different Mesorhizobium strains (Fig. 3). Early induction of senescence in TAL620-induced chickpea nodules (Fig. 4D) raises the question whether there are certain NCR genes in the chickpea genome that cause a toxic effect in the TAL620induced nodule. It is worth mentioning that a toxic effect of NCRs has already been reported in Medicago spp. (Wang et al. 2017; Yang et al. 2017). We detected sporadic spherical-shaped
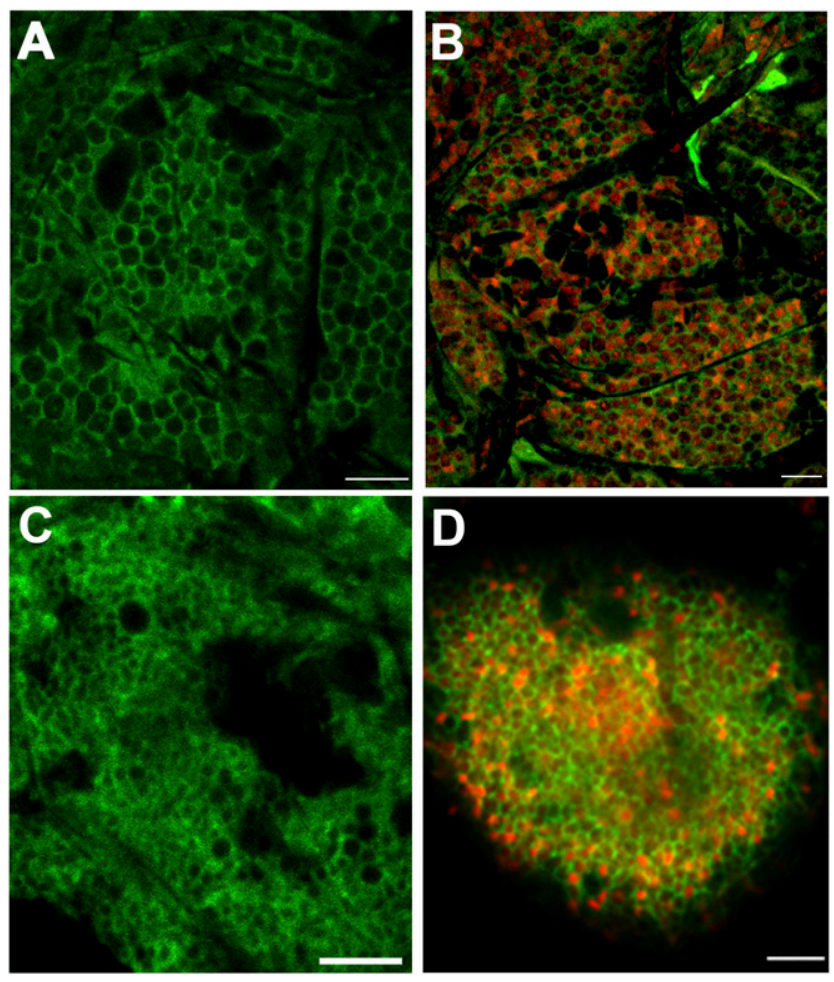

Fig. 4. Characterization of the acidity of the peribacteroid space of chickpea nodules. At 21 days postinoculation, chickpea nodules were hand-sliced and stained with DND189. A, Nodules induced by Mesorhizobium ciceri CC1192 and B, counterstained with SYTO82 (DNA, a live cell). C, Nodules induced by Mesorhizobium ciceri TAL620 and D, counterstained with propidium iodide (DNA of a dead cell). Scale bars in A to $\mathrm{C}=5 \mu \mathrm{m}$ and in $\mathrm{D}=$ $10 \mu \mathrm{m}$. 
dead bacteroids inside TAL620-induced nodules (Fig. 4D). This, together with the late onset of pink coloration and early senescence of the above-mentioned nodules indicate a delay in bacteriod differentiation and reduced survival time. A total of 63 NCRs express in chickpea BDG256 nodules induced by TAL620, as shown by transcriptomic experiments (Kant et al. 2016; Montiel et al. 2017). This suggests that combinations of at least $63 \mathrm{NCRs}$ are required for the development of this uniquely-shaped symbiosome. Our study highlights the importance of further transcriptomic study on chickpea nodules containing normal spherical-shaped symbiosomes. A comparative transcriptomic study between nodules containing spherical and elliptical symbiosomes will highlight the NCRs behind the transition between these two unique shapes. It is also very important to screen diverse chickpea ecotypes inoculated by both TAL620 and CC1192/NI-7 to see whether different hosts can generate different morphotypes of bacteroids.

Overall, our studies with different bacterial strains along with the efficient hairy-root transformation protocol will render the community of nodule biologists a new platform on which genetic experiments of chickpea could easily be performed. Our results presented both in-vitro and ex-vitro methods of chickpea hairy-root transformation, which is more comprehensive than previous publications (Aggarwal et al. 2018; Altinkut et al. 1997; Khawar and Ozcan 2004). Moreover, we have presented enough intriguing features of nodule development in chickpea, which merits further attention in the future.

\section{MATERIALS AND METHODS}

Plant material and growth condition.

Seeds of chickpea (Cicer arietinum) varieties ICC4958 (genome sequenced [Jain et al. 2013] and drought-tolerant genotype), BDG256 (used for nodule transcriptomics by Kant et al. [2016], also known as BG 256), ICC17258 (germplasm accession number ICCV96029, early maturing cultivar), ICC1885 (close relative of ICC1882, used by Varshney et al. [2013] for single nucleotide polymorphism determination), ICC8261 (drought-tolerant genotype used by Varshney et al. [2013]), and local varieties (Desi variety, bought from local market) were surface-sterilized by $30 \%$ commercial bleach solution, containing active sodium hypochlorite $1.2 \%$, for $3 \mathrm{~min}$. The seeds were thoroughly washed with sterile water. They were placed on plates containing sterile wet filter paper for germination. The plates were kept in 20 to $22^{\circ} \mathrm{C}$ temperatures in the dark. After 2 to 3 days, the germinated seedlings were placed in pots with growing substrate (a mixture of 3:1 vermiculite and fire clay balls, leca). The pots were placed in a growth chamber under $200 \mu \mathrm{E} \mathrm{m}^{-2} \mathrm{~s}^{-1}$ with a 16-h light and 8-h dark cycle, at $22^{\circ} \mathrm{C}$ and 40 to $60 \%$ relative humidity. The Desi chickpea variety is characterized by small, brown seeds and is widely cultivated in India (ICC4958, BDG256, ICC17258, and ICC1885) and Kabuli is characterized by large, beige seeds consumed as an international commodity (ICC8261).

\section{Bacterial strains and growth condition.}

The Agrobacterium rhizogenes R1000, ARqua1, and MSU440 strains were grown at $28^{\circ} \mathrm{C}$ in solidified Luria Bertani (LB) medium with appropriate antibiotics. The Agrobacterium strains were transformed with the vectors (pCMU-ERr, pCMUAPr, pCMU-ACTLr, pCMU-MITr, pCMU-PERr, pCMU-GAr, pCMU-PDESr, pm-ck-CFP-CD3-1001, pDR5-GFP-NLS, pCAMBIA2301 and pKGW Red root) (Ivanov and Harrison 2014; Karimi et al. 2002; Nelson et al. 2007; Suzaki et al. 2013) by the freeze-thaw method (Hofgen and Willmitzer 1988). For hairy-root transformation, Agrobacterium strains were grown for $48 \mathrm{~h}$ at $30^{\circ} \mathrm{C}$ on an LB agar plate with suitable antibiotics to produce a lawn in the plate. $M$. ciceri IC59, $M$. ciceri TAL620, M. ciceri CC1192, and Mesorhizobium sp. strain NI-7 were cultivated at $28^{\circ} \mathrm{C}$ in yeast mannitol broth.

\section{Hairy-root transformation.}

Preliminary reports on hairy-root transformation in chickpea (Altinkut et al. 1997; Khawar and Ozcan 2004) using cut radicles encouraged us to initiate our attempt using the same explant. For the in-vitro method of transformation, seeds were surface-sterilized and germinated. For cut-mediated transformation, when seedlings had a radicle length of approximately $40 \mathrm{~mm}$, the radicles were sectioned 10 to $15 \mathrm{~mm}$ from the root tip with a sterile scalpel. The freshly cut root surface of the radicles was coated with $A$. rhizogenes culture by rubbing it on a bacterium lawn containing appropriate vectors. For inject mode of transformation, the germinated seedlings were pierced by a needle (radius $0.45 \mathrm{~mm}$ ) containing A. rhizogenes culture in the tip of the needle. The piercing was done in epicotyl region. After infection by either method, infected seedlings were transferred to a plate containing solidified Fahraeus medium (Boisson-Dernier et al. 2001) without antibiotics. The lower parts of the plates were covered with aluminum foil. The plates were placed longitudinally, allowing the root to grow gravitropically, at $22^{\circ} \mathrm{C}$ under a 16-h light and 8-h dark cycle. After 7 days, hairy root production was noticed. When the transformed roots started emerging from the injection site, nontransformed main roots were removed by cutting with a sterile scalpel, after 14 to 15 dai. Transformed roots were screened under either the Leica stereo fluorescence microscope M205FA equipped with a Leica DFC310FX digital camera (Leica Microsystems) or stereo fluorescence microscope Nikon AZ100 equipped with Nikon digital camera (Nikon digital sight DS-Ri1) (Nikon). For antibiotic selection, after 14 to 15 days, the composite plants were transferred to a solidified Fahraeus medium with suitable antibiotics in culture tubes $(25 \times$ $150 \mathrm{~mm}$ ) and were maintained for 2 weeks. Further, these antibiotic-selected composite plants were transferred to the growing substrate. Alternatively, the composite plants with transformed roots were directly transferred to growing substrate without antibiotic selection after 2 weeks of infection with A. rhizogenes. The growing substrate was pretreated with fullnitrogen B and D medium (Broughton and Dilworth 1971). The plants were bottom-watered four times per week with sterile water. After 10 days of transfer to substrate, the plants were treated with full-nitrogen B and D medium. After 20 days from the initial planting in the growing substrate, composite plants were watered (in the pot) with excess distilled water; further, the composite plants were transferred to a new pot and tray for removal of nitrogen. For 2 to 3 days, the plants were maintained in this nitrogen-free condition and were then inoculated with Mesorhizobium strains for nodulation.

For ex-vitro transformation, plants were grown in pots in $22^{\circ} \mathrm{C}$ in the growth room. A slanted cut $(5$ to $6 \mathrm{~cm})$ was made in the apical stem sections of 25- to 30-day-old plants. The freshly cut stem region was rubbed on a bacterial culture plate (containing $10 \mathrm{mM}$ morpholineethane sulfonic acid, $\mathrm{pH}$ 5.6, and $20 \mu \mathrm{M}$ acetosyringone) of Agrobacterium strains with the appropriate vector. Infected stems were transferred into $4-\mathrm{cm}$ long pots with growing substrate. The pots were placed on a tray containing sufficient full-nitrogen B and D medium to overcome water stress. A humid chamber was created around the tray with clear wrap and the tray was placed in a growth chamber under a 16 -h light and 8 -h dark cycle at $22^{\circ} \mathrm{C}$. Plants were regularly checked for maintaining water and humidity. After 15 days, roots were seen, and, after 30 days, the growing substrate containing plants were washed thoroughly with distilled water and were transferred to a new pot to create 
nitrogen-depleting condition. After maintaining this nitrogen-free condition for 2 to 3 days, the plants was inoculated with Mesorhizobium for nodulation.

\section{GUS staining of chickpea root.}

Histological assay for checking $G U S$ gene expression by GUS activity was performed according to Jefferson et al. (1987). Briefly, hairy roots were vacuum-infiltrated with $0.1 \mathrm{M}$ sodium phosphate buffer containing 0.5 M EDTA, $0.1 \%$ Triton $\mathrm{X}-100,100 \mathrm{mM}$ potassium ferricyanide (III), $1 \mathrm{mg}$ of X-Gluc per milliliter and were then incubated for $10 \mathrm{~h}$ at $37^{\circ} \mathrm{C}$. Expression of the GUS gene in hairy roots was visually assayed and the percentage of transformed roots was calculated.

\section{Nodulation assay.}

The growing substrate was vigorously washed for removal of nitrogen prior to nodulation and was tested for ammoniacal nitrogen and nitrate nitrogen with a soil testing kit (Himedia). The inoculum was prepared from different Mesorhizobium cultures of optical density at $600 \mathrm{~nm}\left(\mathrm{OD}_{600}\right)$ of 0.7 to 0.9 in yeast mannitol medium. The bacterial culture was harvested and was diluted in nitrogen-free B and D media. Each pot was inoculated with $50 \mathrm{ml}$ of diluted 0.03 - to $0.05-\mathrm{OD}_{600}$ bacterial culture in B and D medium.

\section{ARA.}

ARA was performed as described previously (Oke and Long 1999). Briefly, chickpea BDG256 was grown on growing substrate and was inoculated separately with the four Mesorhizobium strains (M. ciceri IC59, M. ciceri TAL620, $M$. ciceri CC1192, and Mesorhizobium sp. NI-7). At 21 and 35 dpi, plants were harvested for ARA. This experiment was repeated four times. For each experiment, five plants were used for ARA for each timepoint. For each plant, the entire root system was placed in a test tube and sealed with suba-seal septa (SigmaAldrich) amd $1 \mathrm{ml}$ of pure acetylene gas was injected through the suba-seal septa. The tubes were kept in the dark at room temperature for $16 \mathrm{~h}$. Ethylene production was measured by gas chromatography (Shimadzu GC-2010 equipped with HPPLOT ' $\mathrm{S}$ ' $\mathrm{Al}_{2} \mathrm{O}_{3} 50 \mathrm{~m}, 0.53 \mathrm{~mm}$ column [Agilent Technologies]). The mean and standard error of mean were calculated between twenty ARA measurement data (four biological replicates and five plants from each experiment). Plants from these experiments were also used for fresh weight determination. A total of 18 plants (three biological replicates and six plants from each experiment) were taken, after $35 \mathrm{dpi}$, for fresh weight. To determine the acetylene reduction activity of the transformed nodules, 10 pCAMBIA2301 ( $p 35 S$ ) vectortransformed plants were used and were inoculated with M. ciceri CC1192.

\section{Confocal microscopy.}

For confocal microscopy, the plants were harvested and the sample was hand-sectioned. The tissues were stained with a $5-\mu \mathrm{M}$ solution of SYTO13 (Invitrogen) and SYTO82 (Invitrogen) and were kept for 15 min in dark. For staining with DND189 (Invitrogen), the tissue was incubated with $100 \mu \mathrm{M}$ DND189 for $15 \mathrm{~min}$. For determination of the status of the bacteroids, the DND189-stained tissue was incubated with a $1 \mathrm{mg} / \mathrm{ml}$ solution of PI for $10 \mathrm{~min}$. Then the samples were washed and mounted with water. The confocal microscopy was performed either on an Olympus Model IX81 or a Leica TCS SP5 confocal microscope, using an excitation wavelength and emission bandpass of $488 \mathrm{~nm}$ and 500 to $530 \mathrm{~nm}$ for SYTO13, $541 \mathrm{~nm}$ and 550 to $580 \mathrm{~nm}$ for SYTO82, 448 and 500 to $530 \mathrm{~nm}$ for DND189, $587 \mathrm{~nm} 600$ to $630 \mathrm{~nm}$ for mCherry, $535 \mathrm{~nm}$ and 610 to $640 \mathrm{~nm}$ for PI.
Isolation of Mesorhizobium strains from chickpea nodules.

The plants were collected from the NIPGR experimental field. Healthy-looking pink nodule-containing plants were selected. Roots were washed thoroughly to remove soil. About 10 pink nodules were collected by cutting the nodules from the root about $0.5 \mathrm{~cm}$ on each side. The nodules were placed in sterile water with $0.12 \mathrm{~g}$ of glass beads and were vortexed for 30 to $60 \mathrm{~s}$ in repetitive cycles to remove adhering soil particles. It was treated with $30 \%$ commercial bleach solution (Hindustan Unilever Limited) containing $1.2 \%$ active sodium hypochlorite for 3 min and was washed with sterile water five or six times. After surface sterilization, the nodules were rolled over solidified yeast mannitol medium and were incubated for 2 to 3 days at $28^{\circ} \mathrm{C}$ (control). Immediately, the same nodules were squashed in sterile water. It was serially diluted with sterile water and was plated in solidified yeast mannitol medium. If the control plate did not show growth, then only the corresponding experimental plates were processed for further characterization. The experimental plates were placed in $28^{\circ} \mathrm{C}$ for 5 to 6 days. The growth was checked regularly. The bacterial colony in the experimental plates were subcultured to purify the bacterial culture and were further used for the nodule developmental experiment.

\section{Cloning of $16 S$ rDNA.}

NI-7 $16 S$ rDNA was amplified by forward 5'-TAACACAT GCAAGTCGAACG-3' and reverse 5'-ACGGGCGGTGTGTAC$3^{\prime}$ primers, using PrimeSTAR Max DNA polymerase (Takara, Clontech). It was then cloned in a pJET 1.2/blunt vector (CloneJET PCR cloning kit; Thermo Fisher). Sanger sequencing was done with sequencing primers provided by the CloneJET PCR cloning kit (forward 5' -CGACTCACTATAGGGAGAGCGGC-3' and reverse $5^{\prime}$-AAGAACATCGATTTTCCATGGCAG-3'). The sequence was assembled and processed with Geneious v9.1.8. The $16 S$ rDNA sequence of the NI-7 strain has been submitted to NCBI (MH517450).

\section{ACKNOWLEDGMENTS}

We thank R. Varshney and S. Gopalakrishnan, ICRISAT, India, S Bhatia, NIPGR-New Delhi, J. Terpolilli, Murdoch University, Australia, for providing $M$. ciceri IC59, $M$. ciceri TAL 620, and $M$. ciceri CC1192, respectively, H. D. Upadhyaya and D. Sastry, ICRISAT, India, for providing chickpea seeds (ICC4958, ICC17258, ICC1882, ICC8261), S. Bhatia, NIPGR for providing BDG256; D. J. Chattopadhyay, Amity University, M. DasGupta of Department of Biochemistry, University of Calcutta, and A. Seal, Department of Biotechnology, University of Calcutta, for their enormous support and allowing us to use their facility; A. Seal for providing the pm-ck CFP CD3 1001 construct, M. DasGupta for providing pCAMBIA2301 vector and A. rhizogenes R1000, M. Udvardi, Nobel Research Institute, Ardmore, OK, U.S.A., for A. rhizogenes ARqua1 and MSU440 strains, M. J. Harrison, Boyce Thompson Institute for Plant Research Ithaca, NY, .US.A., for providing pAtUb-driven subcellular marker constructs and S. Takuya, University of Tsukuba, Tsukuba, Japan, for providing the DR5-GFP-NLS construct; Department of Bio-Technology, University of Calcutta, Interdisciplinary Program of Life Sciences and NIPGR for their confocal facilities, Central Instrument Facility NIPGR, NIPGR-Department of Biotechnology's Electronic Library Consortium for their support; T. Khanna, J. M. Islamia, New Delhi, for technical support; and D. Ghosh, National Institute of Pharmaceutical Education and Research Kolkata, D. Dey, and A. Mukherjee for valuable discussion.

\section{LITERATURE CITED}

Aggarwal, P. R., Nag, P., Choudhary, P., Chakraborty, N., and Chakraborty, S. 2018. Genotype-independent Agrobacterium rhizogenes-mediated root transformation of chickpea: A rapid and efficient method for reverse genetics studies. Plant Methods 14:55.

Altinkut, A., Bajrovic, K., and Gozukirmizi, N. 1997. Regeneration and hairy root formation of chickpea using callus derived plantlets and seedlings. International Chickpea and Pigenpea Newsletter 20:30-31. 
Alunni, B., Kevei, Z., Redondo-Nieto, M., Kondorosi, A., Mergaert, P., and Kondorosi, E. 2007. Genomic organization and evolutionary insights on GRP and NCR genes, two large nodule-specific gene families in Medicago truncatula. Mol. Plant-Microbe Interact. 20:1138-1148.

Armas-Capote, N., Pérez-Yépez, J., Martínez-Hidalgo, P., GarzónMachado, V., Del Arco-Aguilar, M., Velázquez, E., and León-Barrios, M. 2014. Core and symbiotic genes reveal nine Mesorhizobium genospecies and three symbiotic lineages among the rhizobia nodulating Cicer canariense in its natural habitat (La Palma, Canary Islands). Syst. Appl. Microbiol. 37:140-148.

Boisson-Dernier, A., Chabaud, M., Garcia, F., Bécard, G., Rosenberg, C., and Barker, D. G. 2001. Agrobacterium rhizogenes-transformed roots of Medicago truncatula for the study of nitrogen-fixing and endomycorrhizal symbiotic associations. Mol. Plant-Microbe Interact. 14:695-700.

Bonaldi, K., Gherbi, H., Franche, C., Bastien, G., Fardoux, J., Barker, D., Giraud, E., and Cartieaux, F. 2010. The Nod factor-independent symbiotic signaling pathway: Development of Agrobacterium rhizogenes-mediated transformation for the legume Aeschynomene indica. Mol. Plant-Microbe Interact. 23:1537-1544.

Borucki, W. 2007. Proliferation of peroxisomes in pea root nodules-An influence of NaCI- or $\mathrm{Hg}^{2+}$-stress conditions. Acta Soc. Bot. Pol. 76:287-298.

Brijwal, L., and Tamta, S. 2015. Agrobacterium rhizogenes mediated hairy root induction in endangered Berberis aristata DC. Springerplus 4:443.

Broughton, W. J., and Dilworth, M. J. 1971. Control of leghaemoglobin synthesis in snake beans. Biochem. J. 125:1075-1080.

Cai, Y., Chen, L., Liu, X., Sun, S., Wu, C., Jiang, B., Han, T., and Hou, W. 2015. CRISPR/Cas9-mediated genome editing in soybean hairy roots. PLoS One 10:e0136064.

Chandra, R., and Pareek, R. P. 1987. Effect of inoculum rate on the performance of chickpea (Cicer arietinum L.) rhizobium strains in the field. Biol. Fertil. Soils 5:83-87.

Collier, R., Fuchs, B., Walter, N., Kevin Lutke, W., and Taylor, C. G. 2005. Ex vitro composite plants: An inexpensive, rapid method for root biology. Plant J. 43:449-457.

Cutler, S. R., Ehrhardt, D. W., Griffitts, J. S., and Somerville, C. R. 2000. Random GFP:cDNA fusions enable visualization of subcellular structures in cells of Arabidopsis at a high frequency. Proc. Natl. Acad. Sci. U.S.A. 97:3718-3723.

Durgo, H., Klement, E., Hunyadi-Gulyas, E., Szucs, A., Kereszt, A., Medzihradszky, K. F., and Kondorosi, E. 2015. Identification of nodulespecific cysteine-rich plant peptides in endosymbiotic bacteria. Proteomics 15:2291-2295.

Esfahani, M. N., Sulieman, S., Schulze, J., Yamaguchi-Shinozaki, K., Shinozaki, K., and Tran, L. S. 2014. Approaches for enhancement of $\mathrm{N}_{2}$ fixation efficiency of chickpea (Cicer arietinum L.) under limiting nitrogen conditions. Plant Biotechnol. J. 12:387-397.

Estrada-Navarrete, G., Alvarado-Affantranger, X., Olivares, J. E., DíazCamino, C., Santana, O., Murillo, E., Guillén, G., Sánchez-Guevara, N., Acosta, J., Quinto, C., Li, D., Gresshoff, P. M., and Sánchez, F. 2006. Agrobacterium rhizogenes transformation of the Phaseolus spp.: A tool for functional genomics. Mol. Plant-Microbe Interact. 19:1385-1393.

Gavrin, A., Kulikova, O., Bisseling, T., and Fedorova, E. E. 2017. interface symbiotic membrane formation in root nodules of Medicago truncatula: The role of synaptotagmins MtSyt1, MtSyt2 and MtSyt3. Front. Plant Sci. 8:201.

Genre, A., Chabaud, M., Timmers, T., Bonfante, P., and Barker, D. G. 2005. Arbuscular mycorrhizal fungi elicit a novel intracellular apparatus in Medicago truncatula root epidermal cells before infection. Plant Cell 17: 3489-3499.

Haag, A. F., Baloban, M., Sani, M., Kerscher, B., Pierre, O., Farkas, A., Longhi, R., Boncompagni, E., Hérouart, D., Dall'angelo, S., Kondorosi, E., Zanda, M., Mergaert, P., and Ferguson, G. P. 2011. Protection of Sinorhizobium against host cysteine-rich antimicrobial peptides is critical for symbiosis. PLoS Biol. 9:e1001169.

Habibi, P., de Sa, M. F., da Silva, A. L., Makhzoum, A., da Luz Costa, J., Borghetti, I. A., and Soccol, C. R. 2016. Efficient genetic transformation and regeneration system from hairy root of Origanum vulgare. Physiol. Mol. Biol. Plants 22:271-277.

Hanks, J. F., Tolbert, N. E., and Schubert, K. R. 1981. Localization of enzymes of ureide biosynthesis in peroxisomes and microsomes of nodules. Plant Physiol. 68:65-69.

Haskett, T., Wang, P., Ramsay, J., O'Hara, G., Reeve, W., Howieson, J., and Terpolilli, J. 2016. Complete genome sequence of Mesorhizobium ciceri strain CC1192, an efficient nitrogen-fixing microsymbiont of Cicer arietinum. Genome Announc. 4:e00516-16.

He, Z. H., Cheeseman, I., He, D., and Kohorn, B. D. 1999. A cluster of five cell wall-associated receptor kinase genes, Wak1-5, are expressed in specific organs of Arabidopsis. Plant Mol. Biol. 39:1189-1196.
Höfgen, R., and Willmitzer, L. 1988. Storage of competent cells for agrobacterium transformation. Nucleic Acids Res. 16:9877.

Horváth, B., Domonkos, Á., Kereszt, A., Szűcs, A., Ábrahám, E., Ayaydin, F., Bóka, K., Chen, Y., Chen, R., Murray, J. D., Udvardi, M. K., Kondorosi, É., and Kaló, P. 2015. Loss of the nodule-specific cysteine rich peptide, NCR169, abolishes symbiotic nitrogen fixation in the Medicago truncatula dnf7 mutant. Proc. Natl. Acad. Sci. U.S.A. 112: 15232-15237.

Hu, J., Baker, A., Bartel, B., Linka, N., Mullen, R. T., Reumann, S., and Zolman, B. K. 2012. Plant peroxisomes: Biogenesis and function. Plant Cell 24:2279-2303.

Imanishi, L., Vayssières, A., Franche, C., Bogusz, D., Wall, L., and Svistoonoff, S. 2011. Transformed hairy roots of Discaria trinervis: A valuable tool for studying actinorhizal symbiosis in the context of intercellular infection. Mol. Plant-Microbe Interact. 24:1317-1324.

Indurker, S., Misra, H. S., and Eapen, S. 2007. Genetic transformation of chickpea (Cicer arietinum L.) with insecticidal crystal protein gene using particle gun bombardment. Plant Cell Rep. 26:755-763.

Ivanov, S., Fedorova, E. E., Limpens, E., De Mita, S., Genre, A., Bonfante, P., and Bisseling, T. 2012. Rhizobium-legume symbiosis shares an exocytotic pathway required for arbuscule formation. Proc. Natl. Acad. Sci. U.S.A. 109:8316-8321.

Ivanov, S., and Harrison, M. J. 2014. A set of fluorescent protein-based markers expressed from constitutive and arbuscular mycorrhizainducible promoters to label organelles, membranes and cytoskeletal elements in Medicago truncatula. Plant J. 80:1151-1163.

Jain, M., Misra, G., Patel, R. K., Priya, P., Jhanwar, S., Khan, A. W., Shah, N., Singh, V. K., Garg, R., Jeena, G., Yadav, M., Kant, C., Sharma, P., Yadav, G., Bhatia, S., Tyagi, A. K., and Chattopadhyay, D. 2013. A draft genome sequence of the pulse crop chickpea (Cicer arietinum L.). Plant J. 74:715-729.

Jefferson, R. A., Kavanagh, T. A., and Bevan, M. W. 1987. GUS fusions: $\beta$-Glucuronidase as a sensitive and versatile gene fusion marker in higher plants. EMBO J. 6:3901-3907.

Jukanti, A. K., Gaur, P. M., Gowda, C. L., and Chibbar, R. N. 2012. Nutritional quality and health benefits of chickpea (Cicer arietinum L.): A review. Br. J. Nutr. 108 (Suppl 1):S11-S26.

Kant, C., Pradhan, S., and Bhatia, S. 2016. Dissecting the root nodule transcriptome of chickpea (Cicer arietinum L.). PLoS One 11:e0157908.

Karimi, M., Inzé, D., and Depicker, A. 2002. GATEWAY vectors for agrobacterium-mediated plant transformation. Trends Plant Sci. 7: 193-195.

Kereszt, A., Li, D., Indrasumunar, A., Nguyen, C. D., Nontachaiyapoom, S., Kinkema, M., and Gresshoff, P. M. 2007. Agrobacterium rhizogenesmediated transformation of soybean to study root biology. Nat. Protoc. 2: 948-952.

Khawar, K. M., and Ozcan, S. 2004. Hairy-root transformation in Turkish chickpea (Cicer arietinum L) cultivars. Biotechnol. Biotechnol. Equip. 18:51-54.

Kim, M., Chen, Y., Xi, J., Waters, C., Chen, R., and Wang, D. 2015. An antimicrobial peptide essential for bacterial survival in the nitrogenfixing symbiosis. Proc. Natl. Acad. Sci. U.S.A. 112:15238-15243.

Köhler, R. H., Cao, J., Zipfel, W. R., Webb, W. W., and Hanson, M. R. 1997. Exchange of protein molecules through connections between higher plant plastids. Science 276:2039-2042.

Limpens, E., Ivanov, S., van Esse, W., Voets, G., Fedorova, E., and Bisseling, T. 2009. Medicago $\mathrm{N}_{2}$-fixing symbiosomes acquire the endocytic identity marker Rab7 but delay the acquisition of vacuolar identity. Plant Cell 21:2811-2828.

Limpens, E., Ramos, J., Franken, C., Raz, V., Compaan, B., Franssen, H., Bisseling, T., and Geurts, R. 2004. RNA interference in Agrobacterium rhizogenes-transformed roots of Arabidopsis and Medicago truncatula. J. Exp. Bot. 55:983-992.

López, J. J., Camello-Almaraz, C., Pariente, J. A., Salido, G. M., and Rosado, J. A. 2005. Ca2 ${ }^{+}$accumulation into acidic organelles mediated by $\mathrm{Ca}^{2+}$ - and vacuolar $\mathrm{H}^{+}$-ATPases in human platelets. Biochem. J. 390: 243-252.

Mergaert, P., Nikovics, K., Kelemen, Z., Maunoury, N., Vaubert, D., Kondorosi, A., and Kondorosi, E. 2003. A novel family in Medicago truncatula consisting of more than 300 nodule-specific genes coding for small, secreted polypeptides with conserved cysteine motifs. Plant Physiol. 132:161-173.

Mergaert, P., Uchiumi, T., Alunni, B., Evanno, G., Cheron, A., Catrice, O., Mausset, A. E., Barloy-Hubler, F., Galibert, F., Kondorosi, A., and Kondorosi, E. 2006. Eukaryotic control on bacterial cell cycle and differentiation in the rhizobium-legume symbiosis. Proc. Natl. Acad. Sci. U.S.A. 103:5230-5235.

Montiel, J., Downie, J. A., Farkas, A., Bihari, P., Herczeg, R., Bálint, B., Mergaert, P., Kereszt, A., and Kondorosi, É. 2017. Morphotype of 
bacteroids in different legumes correlates with the number and type of symbiotic NCR peptides. Proc. Natl. Acad. Sci. U.S.A. 114:50415046.

Montiel, J., Szűcs, A., Boboescu, I. Z., Gherman, V. D., Kondorosi, É., and Kereszt, A. 2016. Terminal bacteroid differentiation is associated with variable morphological changes in legume species belonging to the inverted repeat-lacking clade. Mol. Plant-Microbe Interact. 29:210-219.

Nelson, B. K., Cai, X., and Nebenführ, A. 2007. A multicolored set of in vivo organelle markers for co-localization studies in Arabidopsis and other plants. Plant J. 51:1126-1136.

Oke, V., and Long, S. R. 1999. Bacterial genes induced within the nodule during the rhizobium-legume symbiosis. Mol. Microbiol. 32:837-849.

Oldroyd, G. E. 2013. Speak, friend, and enter: Signalling systems that promote beneficial symbiotic associations in plants. Nat. Rev. Microbiol. 11:252-263.

Oono, R., and Denison, R. F. 2010. Comparing symbiotic efficiency between swollen versus nonswollen rhizobial bacteroids. Plant Physiol. 154:1541-1548.

Pandey, A., Chakraborty, S., and Chakraborty, N. 2018. Nuclear proteome: Isolation of intact nuclei, extraction of nuclear proteins, and 2-DE analysis. Methods Mol. Biol. 1696:41-55.

Pierre, O., Engler, G., Hopkins, J., Brau, F., Boncompagni, E., and Hérouart, D. 2013. Peribacteroid space acidification: A marker of mature bacteroid functioning in Medicago truncatula nodules. Plant Cell Environ. 36:2059-2070.

Pumplin, N., and Harrison, M. J. 2009. Live-cell imaging reveals periarbuscular membrane domains and organelle location in Medicago truncatula roots during arbuscular mycorrhizal symbiosis. Plant Physiol. 151:809-819.

Quandt, H. J., Puhler, A., and Broer, I. 1993. Transgenic root nodules of Vicia hirsuta. A fast and efficient system for the study of gene expression in indeterminate-type nodules. Mol. Plant-Microbe Interact. 6:699-703.

Ramalingam, A., Kudapa, H., Pazhamala, L. T., Weckwerth, W., and Varshney, R. K. 2015. Proteomics and metabolomics: Two emerging areas for legume improvement. Front. Plant Sci. 6:1116.

Reumann, S. 2004. Specification of the peroxisome targeting signals type 1 and type 2 of plant peroxisomes by bioinformatics analyses. Plant Physiol. 135:783-800.

Riedl, J., Crevenna, A. H., Kessenbrock, K., Yu, J. H., Neukirchen, D., Bista, M., Bradke, F., Jenne, D., Holak, T. A., Werb, Z., Sixt, M., and Wedlich-Soldner, R. 2008. Lifeact: A versatile marker to visualize Factin. Nat. Methods 5:605-607.

Rivas, R., Laranjo, M., Mateos, P. F., Oliveira, S., Martínez-Molina, E., and Velázquez, E. 2007. Strains of Mesorhizobium amorphae and Mesorhizobium tianshanense, carrying symbiotic genes of common chickpea endosymbiotic species, constitute a novel biovar (ciceri) capable of nodulating Cicer arietinum. Lett. Appl. Microbiol. 44:412-418.

Ron, M., Kajala, K., Pauluzzi, G., Wang, D., Reynoso, M. A., Zumstein, K. Garcha, J., Winte, S., Masson, H., Inagaki, S., Federici, F., Sinha, N., Deal, R. B., Bailey-Serres, J., and Brady, S. M. 2014. Hairy-root transformation using Agrobacterium rhizogenes as a tool for exploring cell type-specific gene expression and function using tomato as a model. Plant Physiol. 166:455-469.

Roth, L. E., and Stacey, G. 1989. Bacterium release into host cells of nitrogen-fixing soybean nodules: The symbiosome membrane comes from three sources. Eur. J. Cell Biol. 49:13-23.

Rupela, O. P., and Sudarshana, M. R. 1990. Displacement of native rhizobia nodulating chickpea (Cicer arietinum $\mathrm{L}$.) by an inoculant strain through soil solarization. Biol. Fertil. Soils 3:207-212.

Saint-Jore-Dupas, C., Nebenführ, A., Boulaflous, A., Follet-Gueye, M. L., Plasson, C., Hawes, C., Driouich, A., Faye, L., and Gomord, V. 2006. Plant N-glycan processing enzymes employ different targeting mechanisms for their spatial arrangement along the secretory pathway. Plant Cell 18:3182-3200.

Sinharoy, S., and DasGupta, M. 2009. RNA interference highlights the role of CCaMK in dissemination of endosymbionts in the Aeschynomeneae legume Arachis. Mol. Plant-Microbe Interact. 22:1466-1475.

Sinharoy, S., Pislariu, C. I., and Udvardi, M. K. 2015. A high-throughput RNA interference (RNAi)-based approach using hairy roots for the study of plant-rhizobia interactions. Methods Mol. Biol. 1287:159-178.

Sinharoy, S., Saha, S., Chaudhury, S. R., and Dasgupta, M. 2009. Transformed hairy roots of Arachis hypogea: A tool for studying root nodule symbiosis in a non-infection thread legume of the Aeschynomeneae tribe. Mol. Plant-Microbe Interact. 22:132-142.

Sinharoy, S., Torres-Jerez, I., Bandyopadhyay, K., Kereszt, A., Pislariu, C. I., Nakashima, J., Benedito, V. A., Kondorosi, E., and Udvardi, M. K. 2013. The $\mathrm{C}_{2} \mathrm{H}_{2}$ transcription factor regulator of symbiosome differentiation represses transcription of the secretory pathway gene VAMP721a and promotes symbiosome development in Medicago truncatula. Plant Cell 25:3584-3601.

Sonti, R. V., Chiurazzi, M., Wong, D., and Signer, E. R. 1995. Arabidopsis mutants deficient in T-DNA integration. Proc. Natl. Acad. Sci. U.S.A 92:11786-11790

Stiller, J., Martirani, L., Tuppale, S., Chian, R.-J., Chiurazzi, M., and Gresshoff, P. M. 1997. High frequency transformation and regeneration of transgenic plants in the model legume Lotus japonicus. J. Exp. Bot. 48:1357-1365.

Stougaard, J., Petersen, T. E., and Marcker, K. A. 1987. Expression of a complete soybean leghemoglobin gene in root nodules of transgenic Lotus corniculatus. Proc. Natl. Acad. Sci. U.S.A. 84:5754-5757.

Suzaki, T., Ito, M., and Kawaguchi, M. 2013. Induction of localized auxin response during spontaneous nodule development in Lotus japonicus. Plant Signal. Behav. 8:e23359.

Thilip, C., Soundar Raju, C., Varutharaju, K., Aslam, A., and Shajahan, A. 2015. Improved Agrobacterium rhizogenes-mediated hairy root culture system of Withania somnifera (L.) Dunal using sonication and heat treatment. 3 Biotech 5:949-956.

Thompson, M. V., and Wolniak, S. M. 2008. A plasma membrane-anchored fluorescent protein fusion illuminates sieve element plasma membranes in Arabidopsis and tobacco. Plant Physiol. 146:1599-1610.

Thwe, A., Valan Arasu, M., Li, X., Park, C. H., Kim, S. J., Al-Dhabi, N. A., and Park, S. U. 2016. Effect of different Agrobacterium rhizogenes strains on hairy root induction and phenylpropanoid biosynthesis in tartary buckwheat (Fagopyrum tataricum Gaertn). Front. Microbiol. 7 : 318.

Udvardi, M., and Poole, P. S. 2013. Transport and metabolism in legumerhizobia symbioses. Annu. Rev. Plant Biol. 64:781-805.

Upadhyaya, H. D., Salimath, P. M., Gowda, C. L., and Sube, S. 2007. New early-maturing germplasm lines for utilizationin chickpea improvement Euphytica 157:195-208.

Van-de-Velde, W., Mergeay, J., Holsters, M., and Goormachtig, S. 2003. Agrobacterium rhizogenes-mediated transformation of Sesbania rostrata. Plant Sci. 165:1281-1288.

Varshney, R. K., Song, C., Saxena, R. K., Azam, S., Yu, S., Sharpe, A. G., Cannon, S., Baek, J., Rosen, B. D., Tar'an, B., Millan, T., Zhang, X. Ramsay, L. D., Iwata, A., Wang, Y., Nelson, W., Farmer, A. D., Gaur, P. M., Soderlund, C., Penmetsa, R. V., Xu, C., Bharti, A. K., He, W. Winter, P., Zhao, S., Hane, J. K., Carrasquilla-Garcia, N., Condie, J. A., Upadhyaya, H. D., Luo, M. C., Thudi, M., Gowda, C. L., Singh, N. P., Lichtenzveig, J., Gali, K. K., Rubio, J., Nadarajan, N., Dolezel, J., Bansal, K. C., Xu, X., Edwards, D., Zhang, G., Kahl, G., Gil, J., Singh, K. B., Datta, S. K., Jackson, S. A., Wang, J., and Cook, D. R. 2013. Draft genome sequence of chickpea (Cicer arietinum) provides a resource for trait improvement. Nat. Biotechnol. 31:240-246.

Varshney, R. K., Thudi, M., May, G. D., and Jackson, S. A. 2010. Legume genomics and breeding. Plant Breed. Rev. 33:257.

Wang, D., Griffitts, J., Starker, C., Fedorova, E., Limpens, E., Ivanov, S. Bisseling, T., and Long, S. 2010. A nodule-specific protein secretory pathway required for nitrogen-fixing symbiosis. Science 327:1126-1129

Wang, L., Wang, L., Tan, Q., Fan, Q., Zhu, H., Hong, Z., Zhang, Z., and Duanmu, D. 2016. Efficient inactivation of symbiotic nitrogen fixation related genes in Lotus japonicus using CRISPR-Cas9. Front. Plant Sci. 7:1333.

Wang, Q., Yang, S., Liu, J., Terecskei, K., Ábrahám, E., Gombár, A., Domonkos, A., Szücs, A., Körmöczi, P., Wang, T., Fodor, L., Mao, L., Fei, Z., Kondorosi, É., Kaló, P., Kereszt, A., and Zhu, H. 2017. Hostsecreted antimicrobial peptide enforces symbiotic selectivity in Medicago truncatula. Proc. Natl. Acad. Sci. U.S.A. 114:6854-6859.

Werner, G. D., Cornwell, W. K., Cornelissen, J. H., and Kiers, E. T. 2015 Evolutionary signals of symbiotic persistence in the legume-rhizobia mutualism. Proc. Natl. Acad. Sci. U.S.A. 112:10262-10269.

Xiao, T. T., Schilderink, S., Moling, S., Deinum, E. E., Kondorosi, E., Franssen, H., Kulikova, O., Niebel, A., and Bisseling, T. 2014. Fate map of Medicago truncatula root nodules. Development 141:3517-3528.

Yang, S., Wang, Q., Fedorova, E., Liu, J., Qin, Q., Zheng, Q., Price, P. A., Pan, H., Wang, D., Griffitts, J. S., Bisseling, T., and Zhu, H. 2017 Microsymbiont discrimination mediated by a host-secreted peptide in Medicago truncatula. Proc. Natl. Acad. Sci. U.S.A. 114:6848-6853.

Young, N. D., Debellé, F., Oldroyd, G. E., Geurts, R., Cannon, S. B., Udvardi, M. K., Benedito, V. A., Mayer, K. F., Gouzy, J., Schoof, H., Van de Peer, Y., Proost, S., Cook, D. R., Meyers, B. C., Spannagl, M., Cheung, F., De Mita, S., Krishnakumar, V., Gundlach, H., Zhou, S., Mudge, J., Bharti, A. K., Murray, J. D., Naoumkina, M. A., Rosen, B., Silverstein, K. A., Tang, H., Rombauts, S., Zhao, P. X., Zhou, P., Barbe, V., Bardou, P., Bechner, M., Bellec, A., Berger, A., Bergès, H., Bidwell, S., Bisseling, T., Choisne, N., Couloux, A., Denny, R., Deshpande, S., Dai, X., Doyle, J. J., Dudez, A. M., Farmer, A. D., Fouteau, S., Franken, 
C., Gibelin, C., Gish, J., Goldstein, S., González, A. J., Green, P. J., Hallab, A., Hartog, M., Hua, A., Humphray, S. J., Jeong, D. H., Jing, Y., Jöcker, A., Kenton, S. M., Kim, D. J., Klee, K., Lai, H., Lang, C., Lin, S., Macmil, S. L., Magdelenat, G., Matthews, L., McCorrison, J., Monaghan, E. L., Mun, J. H., Najar, F. Z., Nicholson, C., Noirot, C., O’Bleness, M., Paule, C. R., Poulain, J., Prion, F., Qin, B., Qu, C., Retzel, E. F., Riddle, C., Sallet, E., Samain, S., Samson, N., Sanders, I., Saurat, O., Scarpelli, C., Schiex, T., Segurens, B., Severin, A. J., Sherrier, D. J.,
Shi, R., Sims, S., Singer, S. R., Sinharoy, S., Sterck, L., Viollet, A. Wang, B. B., Wang, K., Wang, M., Wang, X., Warfsmann, J., Weissenbach, J., White, D. D., White, J. D., Wiley, G. B., Wincker, P., Xing, Y., Yang, L., Yao, Z., Ying, F., Zhai, J., Zhou, L., Zuber, A., Dénarié, J., Dixon, R. A., May, G. D., Schwartz, D. C., Rogers, J., Quétier, F., Town, C. D., and Roe, B. A. 2011. The Medicago genome provides insight into the evolution of rhizobial symbioses. Nature 480: 520-524. 